\title{
Alexithymia and Perception of Emotional Information: A Review of Experimental Psychological Findings*
}

\section{La alexitimia y la percepción de la información emocional: Una reseña de resultados de estudios psicológicos experimentales}

Recibido: febrero 11 de 2013 | Revisado: abril 16 de 2013 | Aceptado: junio 16 de 2013

\author{
UTA-SUSAN DONGES \\ ANETTE KERSTING \\ University of Leipzig, Germany \\ THOMAS SUSLOW** \\ University of Leipzig, Germany \\ University of Münster, Münster, Germany
}

doi:10.11144/Javeriana.UPSY13-2.apei

Para citar este artículo: Donges, U. -S., Kersting, A., \& Suslow, T. (2014). Alexithymia and perception of emotional information: A review of experimental psychological findings. Universitas Psychologica, 13(2), 745-756. http://dx.doi.org/10.11144/Javeriana. UPSY13-2.apei

* Agradecimientos: omitir la mención.

*** Deparment of Psychosomatic Medicine. University of Leipzig. Department of Psychiatry, University of Münster, Münster, Germany E-mail: thomas. suslow@medizin.unileipzig.de

\begin{abstract}
A B S T R A C T
Alexithymia represents a personality trait construct characterized primarily by difficulties in the capacity to identify and verbalize emotions. In the present paper, we review the existing results from psychological studies based on behavioral methods with respect to the automatic and controlled processing of external emotional information (i.e. originating outside of the body). There is evidence that alexithymia is associated with impairments in the ability to label and recognize emotional facial expression and lexical stimuli at a controlled processing level. In addition, there is preliminary evidence for a relation between alexithymia and reduced automatic attention allocation to emotional lexical stimuli. In the large majority of previous studies alexithymic characteristics have been assessed by selfreport instruments. To reach stronger conclusions about emotion perception in alexithymia future research has to complement self-descriptive with objective or direct measures of alexithymia such as standardized interview methods. Keywords

alexithymia, perception, emotions, automatic processing, controlled processing, facial stimuli, lexical stimuli

\section{RESUMEN}

La alexitimia representa un constructo de las características de personalidad que se caracteriza principalmente por dificultades para poder identificar y verbalizar emociones. El presente estudio provee una reseña de los resultados de estudios psicológicos basados en métodos conductistas, con respecto al procesamiento automático y controlado de la información emocional externa (es decir, originándose fuera del cuerpo). Se ha comprobado que la alexitimia es un fenómeno asociado a alteraciones en la capacidad de nombrar y reconocer emociones faciales y estímulos léxicos en un nivel de procesamiento controlado. Además, existe evidencia preliminar de una relación entre la alexitimia y un déficit de atención para estímulos léxicos emocionales de tipo automático. En la gran mayoría de estudios anteriores, los rasgos alexitímicos han sido evaluados por instrumentos de autoevaluación. Para poder obtener conclusiones más firmes sobre la percepción de las emociones en la alexitimia, conviene complementar en una investigación futura, medidas autodescriptivas con medidas objetivas o directas de la alexitimia, tales como métodos de entrevistas estandarizados. Palabras clave

Alexitimia, emociones, estímulos faciales, estímulos léxicos, percepción, procesamiento automático, procesamiento controlado.
\end{abstract}


Core features of the personality construct alexithymia are difficulties in the identification and verbalization of emotions. Graeme Taylor (2000) has postulated that the characteristics of the alexithymia construct reflect deficits in the cognitive processing of emotions (see also, Taylor, Bagby, \& Parker, 1997). It is an important theoretical question whether impairments in the perception and identification of interoceptive cues or states (such as subjective feelings) are related to impairments in the perception of external emotional stimuli. It can be theoretically predicted that difficulties in getting aware of body states as developing during emotional reactions should be systematically associated with impairments in the conscious perception of emotional stimuli originating outside of the body. It appears that the subjective evaluation of physiological or body processes occurs with recourse to contextual, environmental information. According to the cognitive-developmental theory of Lane and Schwartz (1987) the same cognitive operations are applied to process internal and external emotional stimuli. Therefore it should be expected that the efficiency in processing internal and external emotional information should be very similar within a person.

In the present article results from psychological studies based on behavioral methods will be reviewed in which automatic and controlled processing of external emotional information was investigated as a function of alexithymia in normal (i.e. non-clinical) individuals. Relevant publications in English language were identified through searches on ISI Web of Science, PsycINFO, and Pubmed (till 2012) and through the reference lists of papers. Only studies were considered in which alexithymia was assessed on the basis of standardized instruments (self-report, objective, or observer-rated measure).

Emotional stimuli can be defined as environmental cues that are capable to elicit emotional reactions or that inform about the emotional state of another person. Basic emotions are in general interpreted as biologically determined processes which are characterized by a specific subjective experience and specific physiological responses, action tendencies, and expressive reaction patterns (Ekman, 1984; Izard, 1977; Plutchik, 1994). Emotional facial expressions are an important part of non-verbal communication used in everyday life. As early as five months old, infants are able to differentiate between the facial expressions of anger, fear, sadness, and surprise (Schwartz, Izard, \& Ansul, 1985; Serrano, Iglesias, \& Loeches, 1992). In his differential emotions theory Izard $(1972,1977)$ proposed a set of ten basic emotions (interest, joy, surprise, anger, contempt, disgust, fear, sadness, shame, and guilt).

In everyday life emotional reactions are normally elicited without intention or awareness. They appear to develop spontaneously and without effort (Rohracher, 1960; Zajonc, 1980). Perceptual cognitive processes which carry out an automatic evaluation of the environment precede emotional reactions. It has been shown that emotional facial expression or emotionally valenced words presented below the threshold of conscious awareness can influence the processing of subsequently shown stimuli (Greenwald, Klinger, \& Liu, 1989; Murphy $\&$ Zajonc, 1993). It has a high adaptive value for an organism to react without effort and efficiently to stimuli which have significance for its survival or wellbeing (Öhman, 1987; Öhman, Flykt, \& Lundqvist, 2000). Research on alexithymia has to clarify whether alexithymic persons show impairments in the processing of emotional information already at an automatic processing level or whether controlled processing is primarily impaired.

The differentiation between controlled and automatic information processing, one of the central concepts in cognitive psychology, has been repeatedly confirmed (Anderson, 1989; Shiffrin \& Schneider, 1977). An automatic process can be defined as being involuntary, unintentional, autonomous, occurring outside of awareness. In other words, it could occur without the need of an act of will, without the individual's awareness of its commencement or operation, and without interfering with other, concurrent processes (Shiffrin \& Schneider, 1977). Anxiety disorders, for example, appear to be primarily characterized by processing abnormalities at the automatic or 
implicit perception level which has also been interpreted as cognitive vulnerability (Williams, 1997). In contradistinction, a controlled process is defined as under intentional control, with the individual aware of their occurrence, effortful, and limited by the availability of processing resources (Neely, 1977).

\section{Psychological assessment of emotion processing characteristics}

\section{Tasks measuring controlled processing of emotional information}

\section{Identification and labeling of emotional}

facial expression and emotional situations

The assessment of the capacity to identify and label facial emotions is one of the classical tasks developed by experimental emotion psychologists. Typically, in the so-called matching tasks faces with an emotional expression are presented and have to be assigned to a face expressing the same emotion quality. Labeling tasks are used to assess the ability of individuals to express in words facially expressed emotions (see Table 1). There exist free as well as forced-choice response formats in which the response to an item is selected from a list of words denoting emotion. In language-based tasks sentences are presented describing situations that elicit a specific emotional reaction (without including words denoting emotions). In these tasks subjects have to decide which emotion word, emotional facial expression or picture can describe best the emotional reaction elicited (Lane et al., 1996).

\section{Emotion situation priming}

It has been shown that reading descriptions of emotional situations can facilitate and speed up the processing of subsequently presented emotion words (Conway \& Bekerian, 1987). A task that allows assessing the effects of reading depictions of emotional situations in a standardized manner is emotion situation priming. In case of the lexical decision task variant sentences describing an emotional situation are presented and after an interval of $500 \mathrm{msec}$ a lexical stimulus is shown that has to be classified as word or non-word. If the emotion word fits with the emotion situation then a faster lexical decision can be expected compared to the mismatch condition. Since in this task the interstimulus interval is rather long it is likely that primarily controlled information processing is assessed.

\section{Tasks measuring automatic processing of emotional information}

\section{Emotional Stroop tasks}

Stroop (1935) developed a color-word test to measure processes of selective attention and interference. In the classical color-word interference test observers are slower to identify the color of ink when the ink is used to produce color names different from the ink. For example, observers are slower to identify green ink when it spelled the word yellow. The difference in time for reading the words printed in colors and the same words printed in black is a measure of the interference. In the case of emotional Stroop tasks subjects have to name

\section{TABLE 1}

Experimental paradigms used in alexithymia research to measure controlled and automatic emotion processing

\begin{tabular}{ll}
\hline \multicolumn{1}{c}{ Controlled processing } & \multicolumn{1}{c}{ Automatic processing } \\
\hline Recognition of facial and lexical emotional information & attention allocation, identification of valence, implicit processing effects \\
- Matching tasks & - emotional Stroop tasks \\
- Labeling tasks & - sequential affective priming tasks \\
- Emotion situation priming & - perception of chimeric faces \\
\hline
\end{tabular}

Source: own work 
the color of emotional words (e.g., hostile or honest) which are clearly visible or which can be also presented subliminally (below the threshold of subjective awareness) in computer-based tasks. It was observed that negative (but also positive) words are color named more slowly than neutral words (Pratto \& John, 1991; Rothermund, Wentura, \& Bak, 1996). This effect appears to occur independently of conscious processing strategies (Pratto, 1994). Emotional Stroop tasks seem to assess the extent of involuntary attention allocation to emotional stimuli (Williams, Mathews, \& MacLeod, 1996).

\section{Sequential affective priming}

Fazio, Sanbonmatsu, Powell, and Kardes (1986) proposed an experimental procedure in which emotional stimuli are presented briefly one after the other. If the stimulus onset asynchrony is less than $300 \mathrm{msec}$ it can be assumed that automatic processing effects (i.e. affective priming effects) are measured. In affective priming tasks emotional faces or words can be used as stimuli. Different tasks have been proposed with respect to the second stimulus (i.e. the target): evaluative decision (positive or negative), pronunciation, or lexical decision (in case of lexical stimuli). The experimental effects typically observed are processing facilitation in case of valence congruence between prime and target and processing inhibition in case of valence incongruence (Hermans, de Houwer, \& Eelen, 1994). However, under specific experimental conditions a main effect of processing inhibition due to negative prime stimuli is obtained (Suslow, Ohrmann, \& Arolt, 2001).

\section{Chimeric faces}

Emotions are expressed more intensely on the left side of the face than on the right side. A chimeric face is created by dividing an image of a face vertically through the midline. Such a face might be half neutral and half happy. Typically, flashing two chimeric faces for brief intervals, the subject is asked to specify which member of the pair looked happier (e.g., Heller \& Levy, 1981). Judgments made on chi- meric faces elicit reliably a perceptual bias to the left hemispace, presumed to be due to right hemisphere dominance for emotional processes. Since subjects are essentially unaware of the chimeric nature of the stimuli chimeric face tasks assess primarily characteristics of automatic emotion perception.

\section{Alexithymia and the controlled processing of emotional facial expression}

McDonald and Prkachin (1990) conducted one of the first studies on the perception of emotional facial expression and emotional pictures as a function of alexithymia. Twenty males assessed as alexithymic or not, on the basis of the Schalling-Sifneos Personality Scale ([SSPS]; Martin, Pihl, \& Dobkin, 1984), rated the emotional impact of prototypic displays of emotion. Emotional stimuli were presented for 10 seconds. The alexithymic men did not differ from the non-alexithymic men in labeling facial expressions using a list of six basic emotions or in evaluating scenarios that elicit positive or negative emotions. The findings of McDonald and Prkachin's study showed that alexithymic individuals do have a cognitive representation of emotional information and recognize and respond appropriately to linguistic conventions concerning emotion. However, because of the small sample size statistical power to detect performance differences was rather limited. Another important limitation of McDonald and Prkachin's study is the use of the SSPS as measure of alexithymia which appears to be characterized by low internal consistency (Parker, Taylor, Bagby, \& Thomas, 1991).

In 1990, Mayer, di Paolo, and Salovey published data from an experiment in which young adults had to evaluate visual cues (among other stimuli facial expressions of six basic emotions) using a list of emotion words. Surprisingly, positive correlations were observed between TAS-alexithymia and larger emotional range in evaluating visual stimuli and higher intensity of emotional reactions. The influence of negative state emotions was not controlled in this experiment.

In a subsequent study Parker, Taylor, and Bagby (1993a) presented facial expressions of several 
basic emotions to a sample of university students with the task to evaluate type and intensity of the experienced emotions. The 20-Item Toronto Alexithymia Scale ([TAS-20]; Bagby, Parker, \& Taylor, 1994) was applied as a measure of alexithymia. For the emotions of fear, contempt, interest, anger, distress, surprise, and joy high alexithymic individuals were less able to recognize facial expressions than low alexithymic individuals. The effect of negative state emotions on recognition performance was not controlled in this experiment. The results of another study (Mann, Wise, Trinidad, \& Kohanski, 1994) based on a non-clinical sample show also that high alexithymics (as defined by the TAS-26; Taylor, Ryan, \& Bagby, 1985) are less able to identify emotional facial expression than low alexithymics.

Berenbaum and Prince (1994) used the Profile of Nonverbal Sensitivity (PONS) to examine the effects of the TAS scales Difficulties in identifying feelings and Difficulties in describing feelings on the perception of emotional information in a sample of university students. Subjects had to judge photographs of faces and people's bodies on two dimensions (i.e. dominance and positivity). Berenbaum and Prince found no evidence for an influence of alexithymic characteristics on the accuracy of interpreting emotion-relevant information. However, the authors reported a correlation between alexithymic features and interpretative biases. Individuals who had difficulties to recognize their emotions were less likely to select anger and more likely to select disgust than individuals with low alexithymia.

Using the TAS-20, Pandey and Mandal (1997) selected a group of high-alexithymic individuals and a control group from a large non-clinical sample. The two study groups did not differ with respect to their ability to recognize and to label facial expressions of basic emotions.

Lane et al. (1996) applied the TAS-20 as well as the Levels of Emotional Awareness Scale ([LEAS]; Lane, Quinlan, Schwartz, Walker, \& Zeitlin, 1990) and investigated the relationship between alexithymic features and the ability to label and identify facial emotions. The LEAS evaluates the degree of differentiation and integration of words denoting emotion and the degree of awareness of emotional complexity in self and others. In a sample representative of the general population $(N=308)$ it was found that high TAS-20 scores (and low LEAS scores) were associated with poor recognition of emotional facial expressions. Even though these correlations were highly significant strength of correlations was only moderate (correlation coefficients were between -0.27 and 0.39). Negative state emotions did not affect significantly the relationship between alexithymia and perception of facial expression. The results of a subsequent study (Lane, Sechrest, Riedel, Shapiro, \& Kaszniak, 2000) corroborate the above mentioned findings. It was shown that there exist inverse correlations between alexithymia and the ability to recognize the facial expression of basic emotions (joy, sadness, fear, anger, disgust, and surprise).

Finally, it was investigated if alexithymic characteristics affect the perception of emotional facial expression under rapid presentation conditions (Parker, Prkachin, \& Prkachin, 2005). To this aim, the authors showed neutral, angry, sad, and fearful faces to a sample of university students. Study participants had to decide whether a briefly shown face depicted an emotion or not. According to the results of Parker et al. (2005) difficulties describing feelings were negatively correlated with the ability to detect facial expressions of negative emotion in the speeded condition. This correlation was independent of negative and positive affectivity. Thus, the alexithymic personality trait difficulties in describing feelings appears to be associated with the perception of negative emotion displayed by others in circumstances that require rapid and sensitive use of information processing.

Summing up the results of previous research it can be concluded that there is evidence for an association between alexithymia and controlled processing of emotional facial expression from five studies. Especially the studies of Lane et al. $(1996,2000)$ which are of high methodological quality and are based on large representative samples corroborate the assumption that alexithymic personality traits are related to a poor ability to recognize and label emotional facial 
expression. However, since four studies did not find a relationship between alexithymia and controlled processing of facial emotions it appears that this association could be of modest strength and therefore not always detectable. There are data suggesting that alexithymics' deficit in the ability to detect (negative) emotions in other people may not be manifest unless demands in the form of temporal constraints are placed on emotion processing capacities.

\section{Alexithymia and the Controlled Processing of Emotional Linguistic Stimuli}

Less research has been conducted on the perception of emotional linguistic stimuli compared to the perception of emotional faces. Berenbaum and Prince (1994) applied the Emotional Story Test to examine the effects of the alexithymic personality traits difficulties in identifying feelings and difficulties in describing feelings on the perception of emotional stories. No relationship was observed between alexithymic characteristics and the accuracy of interpreting emotional stories. Lane et al. (1996) administered descriptions of emotion eliciting scenarios in their study on alexithymia and information processing. High TAS-20 and low LEAS scores were correlated with poor interpretation of lexical emotional stimuli. Again, correlations were statistically highly significant but strength of correlations was only moderate.

In the study of Suslow and Junghanns (2002) an emotion situation priming task was used to investigate whether alexithymics are impaired in linking emotion eliciting scenarios and emotion concepts. An inverse correlation between TAS20 and emotional situation priming was found. In particular, difficulties in identifying feelings were associated with low priming from situational information to emotion words.

In sum, findings from previous research indicate that alexithymic personality traits are associated with impairments in the controlled processing of lexical emotional stimuli.

\section{Alexithymia and the Automatic Processing of Emotional Facial Expression}

\section{Alexithymia and Affective Priming Effects}

To our knowledge only two affective priming studies to date have addressed the effect of alexithymia on the automatic perception of facial emotions. In a sequential affective priming task based on happy, sad, and neutral prime faces no association between TAS-20 and affective priming due to facial emotions was observed (Suslow, Junghanns, Donges, \& Arolt, 2001). In this study targets were also emotional faces which had to be evaluated as positive or negative. However, there was a negative correlation between LEAS and affective priming due to facial emotions. That means that individuals with a low awareness of emotional complexity showed stronger processing facilitation due to emotional face primes than individuals with a high awareness of emotional complexity. The latter could spontaneously allocate more attention to emotional faces.

Vermeulen, Luminet, and Corneille (2006) administered a sequential affective priming task using schematic face drawings with neutral, happy, sad, and angry expressions as prime stimuli and emotional words as target stimuli to a sample of university students. In their experiments an inverse relation of TAS-20 and affective priming due to angry faces was found. Thus, high alexithymic individuals tended to exhibit low automatic processing facilitation due to angry facial expression. Interestingly, no correlations were observed between TAS-20 and affective priming due to sad or happy facial expression.

The results of both studies conducted hitherto suggest that (TAS-20) alexithymia could be related to an impaired automatic processing of threatening (but not sad or happy) facial expression. In addition, a low awareness of emotional complexity seems to be associated with an enhanced priming due to sad and happy facial expression which might be caused by a reduced automatic allocation of attention towards emotional facial expression. 
Alexithymia and the Perception of Chimeric Faces

Berenbaum and Prince (1994) presented the free-vision Chimeric Face Task to a sample of university students to examine hemi-spatial bias as a function of alexithymia. In this task subjects saw two chimeric faces (one of which has a smile on the right side and the other having a smile on the left side) and had to choose which looks happier. The free-vision Chimeric Face Task consists of 36 pairs of faces that are each presented for a time period of up to ten seconds. In the whole sample, there were no significant correlations between difficulties in identifying and describing feelings and hemi-spatial bias. However, individuals with high alexithymia scores showed an impaired perception of chimeric faces. In addition, for men an association of difficulties in identifying feelings and hemi-spatial bias was detected. For women, a relationship between difficulties in describing feelings and hemi-spatial bias was observed. The alexithymic characteristics were associated with a reduced left hemi-face bias suggesting that individuals with higher levels of alexithymia have less right hemisphere activity than other individuals. The concept left hemi-face bias refers to a perceptual effect shown by normal right handed subjects meaning that a chimeric face with the emotional side on the left is judged as more emotional than a face with the emotional side on the right. Jessimer and Markham (1997) selected based on the TAS20 individuals with high and low alexithymia scores. The authors used chimeric pictures of real and schematic faces in the experiment. The high alexithymics exhibited a reduced left hemi-face bias compared to the low alexithymics. Finally, Lane, Kivley, Du Bois, Shamasundara, and Schwartz (1995) administered the Levy Chimeric Faces Test together with the LEAS to a group of university students. A positive correlation was obtained between left hemi-face bias and awareness of emotional complexity. Persons with a high awareness of emotional complexity manifested an enhanced right-hemispheric dominance in the perception of facial emotion.
Taken together, there is clear evidence that alexithymic personality traits are associated with reductions in left hemi-face bias when perceiving chimeric faces. Thus, alexithymia appears to be characterized by an impaired processing of emotional information by the right cerebral hemisphere.

\section{Alexithymia and the Automatic Processing of Emotional Linguistic Stimuli}

\section{Alexithymia and Emotional Stroop Effects}

Parker, Taylor, and Bagby (1993b) were the first who administered an emotional Stroop task to investigate the involuntary processing of lexical emotional cues as a function of alexithymia. It was found that alexithymic individuals (as defined by scores on the TAS-20) were more distracted by arousal words than non-alexithymic individuals. According to Parker et al. (1993b) the data are consistent with the view that alexithymia reflects a deficit in the ability cognitively to process and modulate emotional stimuli. They argued that cognitive schemata that assimilate emotional arousal are poorly differentiated and not flexible or well integrated in alexithymic individuals. Findings from an emotional Stroop study conducted in India (Pandey, 1995) are in line with those of Parker et al. (1993b).

Lundh and Simonsson-Sarnecki (2002) administered an emotional Stroop task in which illness and negative emotion words were presented masked and unmasked. A large sample of normal subjects was investigated $(N=120)$. In the unmasked presentation condition word stimuli were shown on the screen until response. In the masked presentation condition words were presented for 17.34 or $51 \mathrm{msec}$ masked by letters of the same color so that subjects were not able to perceive the word consciously. No correlations were found between TAS-20 and performance on the emotional Stroop task. The authors formed extreme groups by selecting the 20 participants who scored highest (or lowest) on the TAS-20. Group comparisons between low TAS and high TAS scorers indicated that the alexithymic individuals were slower on color-naming unmasked 
illness words than negative words. However, no relationship was observed between alexithymia and the automatic processing of emotional words.

Sanchez and Serrano (1997) examined a sample of university students with an emotional Stroop task in which negative arousal words were presented. In this study, alexithymic individuals were less distracted by emotional words than non-alexithymic individuals. These results are not in line with those of Parker et al. (1993b) and Pandey (1995). According to Sanchez and Serrano alexithymic subjects cannot efficiently identify emotional stimuli so that these stimuli do not enter into subsequent processing stages and thus do not interfere with other processes such as color-naming. The findings of Coffey, Berenbaum, and Kerns (2003) who also examined a sample of university students corroborate the results of Sanchez and Serrano (1997): individuals who reported devoting greater attention to their emotions paid more attention to emotion words in the Stroop task (as indicated by longer times to color-name emotion words).

In the study of Müller, Alpers, and Reim (2006) an emotional Stroop task was administered and alexithymia was assessed using a self-rating (TAS20) and observer-rating ([OAS]; Haviland, Warren, \& Riggs, 2000). In the study of Müller et al (2006). both measures of alexithymia were positively correlated. The main finding was that subjects with high observer-rated alexithymia had a lesser emotional bias in the emotional Stroop experiment. They had lower interference scores for body symptoms and negative words than subjects rated low on alexithymia. Thus, low alexithymic individuals seem to allocate spontaneously more attention especially to body symptoms than high alexithymics. Since no relationship was found between self-reported alexithymia and performance on the emotional Stroop task the results of Müller et al. (2006) further stress the importance of a multimethod assessment of alexithymia with self-reports and observer ratings.

The findings of the six studies presented above are not very consistent. The heterogeneous pattern of results could at least in part be due to the different versions of the Stroop task applied (e.g., single trial vs. card format; Kindt, Bierman, \& Brosschot, 1996) and the poor control of participants' state and trait emotions. All in all, alexithymic personality traits seem to be associated with reduced distraction due to emotionally valenced words. Such an assumption is also supported by the results of the study of Müller et al. (2006) in which an observer-rated measure was used to assess alexithymia.

\section{Alexithymia and Affective Priming Effects}

Two studies were conducted in Germany to examine the effect of alexithymic personality traits on the automatic processing of lexical emotional stimuli (Suslow, 1998; Suslow et al., 2001). In these sequential priming experiments a positive, negative, or neutral word was shown for $200 \mathrm{msec}$. Then, after an interval of $100 \mathrm{msec}$ a second word (the target) was presented that had a positive or negative valence. The second word had to be pronounced as fast as possible or had to be evaluated as positive or negative. By presenting the emotional (and neutral) prime words for very brief periods of time automatic processing effects could be revealed. Reaction latencies and error rates were registered for all prime-target conditions and priming effects were calculated by comparing performance in the emotion prime conditions with that in the neutral prime condition. In the above mentioned studies evidence was found that subjects with high TAS-20 scores direct less attention to negative words compared to subjects with low TAS-20 scores. Alexithymic individuals appear to be able to evaluate the affective meaning of word stimuli automatically but further processing of the emotion words seems to be reduced at an automatic processing level.

According to the results of a study conducted in Belgium (Vermeulen et al., 2006) there is no relationship between alexithymia and affective priming based on lexical stimuli. Thus, no firm conclusions can be drawn at present about the relationship between alexithymia and affective priming based on lexical emotional stimuli. 


\section{Summary and Conclusions}

The majority of the existing alexithymia studies based on behavioral experimental methods were focused on the controlled processing of emotional facial expression. Starting from early infancy, facial emotions play a central role in the regulation of interpersonal interactions. This research interest could have developed because it has been postulated that impairments in the cognitive processing of emotional information could originate from early deficits in non-verbal communication between parents and their children (Taylor \& Bagby, 2000). It is very important that parents are responsive to their child's facial expression of emotions. The facial reactions of the parents inform children about their own feelings and emotional conditions and about the emotional state of significant others. Parental neglect and emotional deprivation are discussed as central factors in the development of alexithymic personality characteristics.

The emotional Stroop task was primarily used to assess automatic emotion processing in alexithymia. This line of research explored the involuntary processing of lexical emotional stimuli. The generalizability of the present findings is low because in many studies participants were university students. Moreover, in the majority of the studies self-report measures (e.g., the Toronto-Alexithymia-Scale) were applied to assess alexithymic personality traits. The utility of the self-description is founded on the assumption that people can accurately recognize and describe their feelings. There exist serious doubts that valid judgments about the ability to monitor, identify, and verbalize emotional states can be obtained especially from highly alexithymic individuals (Lane et al., 1996). Thus, the present findings have to be interpreted as preliminary since they strongly depend on the self-report approach.

In sum, based on our review of the existing literature it can be concluded that alexithymia is associated with impairments in the ability to label and recognize emotional facial expression at a controlled processing level. Difficulties identifying and describing one's feelings appear to be related to impairments in the (conscious) processing of other persons' emotional facial expression. Possibly, marked processing deficits occur in alexithymic individuals when facial emotions have to be recognized rapidly. There are up to now no solid results on the relationship between alexithymia and automatic perception of facial emotions. The findings of the two previous affective priming studies were not homogeneous. However, there is evidence that alexithymic individuals exhibit a reduced left hemiface bias when perceiving chimeric faces indicating a poor processing of emotional information by the right cerebral hemisphere in alexithymia.

In addition, there is preliminary evidence for a relation between alexithymia and impaired controlled processing of emotional lexical stimuli. That is, individuals with difficulties in identifying and describing feelings manifest impairments in recognizing emotions from lexical stimuli (e.g., stories, situational scenarios). Furthermore, first evidence has been provided that high alexithymic subjects allocate less attention to emotional lexical stimuli at an automatic processing level than low alexithymic subjects.

Thus, when considering the existing literature there are quite strong indications that alexithymic characteristics are associated with impairments in the controlled processing of facial and lexical emotion stimuli. The empirical evidence for automatic emotion processing dysfunction in alexithymia is less compelling. However, it appears that alexithymic subjects exhibit primarily deficits in the automatic processing of lexical emotion stimuli. It seems that impairments in the perception of interoceptive and exteroceptive emotion stimuli do co-occur albeit the extent of association between interoception and exteroception of emotions appears rather moderate.

Using a multi-method approach, future research should combine self-report and observer-rated instruments to measure alexithymic personality characteristics. In this way, interpretation of behavioral experimental findings could be significantly extended and improved in studies on alexithymia. Moreover, it appears necessary to examine in the future also high alexithymic subjects suffering from psychiatric or psychosomatic disorders. Possibly, 
these clinical groups could be characterized by pronounced (combinations of) impairments in the automatic as well as in the controlled processing of emotional information. Today, very little is known about the relationship of automatic and controlled emotion processing in alexithymia. Future studies on alexithymia combining tasks that measure automatic and controlled emotion processing will yield new insights into the coupling of deficits at different processing levels. Future research on alexithymia should pay more attention to the impairments in automatic emotion processing. It is widely accepted that in general emotions are involuntarily elicited. Deficits at early perceptual emotional processing stages should systematically affect higher information processing since the former constitute the input to more complex operations of information processing. The experimental methods of emotion psychology could be combined with modern neuroimaging techniques such as functional magnetic resonance imaging to elucidate the neurobiological substrate of alexithymic personality characteristics.

\section{References}

Anderson, J. R. (1989). Kognitive Psychologie: eine Einführung. Heidelberg: Spektrum-der-Wissenschaft.

Bagby, R. M., Parker, J. D., \& Taylor, G. J. (1994). The twenty-item Toronto Alexithymia Scale-I. Item selection and cross-validation of the factor structure. Journal of Psychosomatic Research, 38(1), 23-32.

Berenbaum, H., \& Prince, J. D. (1994). Alexithymia and the interpretation of emotion-relevant information. Cognition 82 Emotion, 8(3), 231-244.

Coffey, E., Berenbaum, H., \& Kerns, J. G. (2003). The dimensions of emotional intelligence, alexithymia, and mood awareness: Associations with personality and performance on an emotional Stroop task. Cognition Eु Emotion, 17(4), 671-679.

Conway, M. A., \& Bekerian, D. A. (1987). Situational knowledge and emotions. Cognition $\mathbb{E}$ Emotion, 1(2), 145-191.

Ekman, P. (1984). Expression and the nature of emotion. In K. R. Scherer \& P. Ekman (Eds.), Approaches to emotion (pp. 319-344). Hillsdale, NJ: Erlbaum.
Fazio, R. H., Sanbonmatsu, D. M., Powell, M. C., \& Kardes, F. R. (1986). On the automatic activation of attitudes. Journal of Personality and Social Psychology, 50(2), 229-238.

Greenwald, A. G., Klinger, M. R., \& Liu, T. J. (1989). Unconscious processing of dichoptically masked words. Memory E Cognition, 17(1), 35-47.

Haviland, M. G., Warren, W. L., \& Riggs M. L. (2000). An observer scale to measure alexithymia. Psychosomatics, 41(5), 385-392.

Heller, W., \& Levy, J. (1981). Perception and expression of emotion in right-handers and left-handers. Neuropsychologia, 19(2), 263-272.

Hermans, D., De Houwer, J., \& Eelen, P. (1994). The affective priming effect: Automatic activation of evaluative information in memory. Cognition $\mathbb{E}$ Emotion, 8(6), 515-533.

Izard, C. E. (1972). Patterns of emotions: A new analysis of anxiety and depression. New York: Academic Press.

Izard, C. E. (1977). Human emotions. New York: Plenum Press.

Jessimer, M., \& Markham, R. (1997). Alexithymia: A right hemisphere dysfunction specific to recognition of certain facial expressions? Brain and Cognition, 34(2), 246-258.

Kindt, M., Bierman, D., \& Brosschot, J. F. (1996). Stroop versus Stroop: Comparison of a card format and a single-trial format of the standard color-word Stroop task and the emotional Stroop task. Personality and Individual Differences, 21(5), 653-661.

Lane, R. D., Kivley, L. S., Du Bois, M. A., Shamasundara, P., \& Schwartz, G. E. (1995). Levels of emotional awareness and the degree of right hemispheric dominance in the perception of facial emotion. Neuropsychologia, 33(5), 525-538.

Lane, R. D., Quinlan, D. M., Schwartz, G. E., Walker, P. A., \& Zeitlin, S. B. (1990). The Levels of Emotional Awareness Scale: A cognitive-developmental measure of emotion. Journal of Personality Assessment, 55(1-2), 124-134.

Lane, R. D., \& Schwartz, G. E. (1987). Levels of emotional awareness: A cognitive-developmental theory and its application to psychopathology. The American Journal of Psychiatry, 144(2), 133-143.

Lane, R. D., Sechrest, L., Reidel, R., Weldon, V., Kaszniak, A., \& Schwartz, G. E. (1996). Impaired verbal 
and nonverbal emotion recognition in alexithymia. Psychosomatic Medicine, 58(3), 203-210.

Lane, R. D., Sechrest, L., Riedel, R., Shapiro, D. E., \& Kaszniak, A. W. (2000). Pervasive emotion recognition deficit common to alexithymia and the repressive coping style. Psychosomatic Medicine, 62(4), 492-501.

Lundh, L. G., \& Simonsson-Sarnecki, M. (2002). Alexithymia and cognitive bias for emotional information. Personality and Individual Differences, 32(6), 1063-1075.

Mann, L. S., Wise, T. N., Trinidad, A., \& Kohanski, R. (1994). Alexithymia, affect recognition, and the five-factor model of personality in normal subjects. Psychological Reports, 74(2), 563-567.

Martin, J. B., Pihl, R. O., \& Dobkin, P. (1984). SchallingSifneos personality scale: findings and recommendations. Psychotherapy and Psychosomatics, 41(3), 145-152.

Mayer, J. D., DiPaolo, M., \& Salovey, P. (1990). Perceiving affective content in ambiguous visual stimuli: A component of emotional intelligence. Journal of Personality Assessment, 54(3-4), 772-781.

McDonald, P. W., \& Prkachin, K. M. (1990). The expression and perception of facial emotion in alexithymia: A pilot study. Psychosomatic Medicine, 52(2), 199-210.

Müller, J., Alpers, G. W., \& Reim, N. (2006). Dissociation of rated emotional valence and Stroop interference in observer-rated alexithymia. Journal of Psychosomatic Research, 61(2), 261-269.

Murphy, S. T., \& Zajonc, R. B. (1993). Affect, cognition, and awareness: Affective priming with optimal and suboptimal stimulus exposures. Journal of Personality and Social Psychology, 64(5), 723-739.

Neely, J. H. (1977). Semantic priming and retrieval from lexical memory: Roles of inhibitionless spreading activation and limited-capacity attention. Journal of Experimental Psychology: General, 106(3), 226-254.

Öhman, A. (1987). The psychophysiology of emotion: An evolutionary-cognitive perspective. In P. K. Ackles (Ed.), Advances in psychophysiology: A research annual (pp. 79-127). Greenwich: JAI Press.

Öhman, A., Flykt, A., \& Lundqvist, D. (2000). Unconscious emotion: Evolutionary perspectives, psychophysiological data, and neuropsychological mechanisms. In R. D. Lane \& L. Nadel (Eds.), Cognitive neuroscience of emotion (pp. 296-327). New York: Oxford University Press.

Pandey, R., \& Mandal, M. K. (1997). Processing of facial expressions of emotion and alexithymia. The British Journal of Clinical Psychology, 36(4), 631-633.

Pandey, R. (1995). Stroop interference effect of emotionarousing words in alexithymia. Journal of the Indian Academy of Applied Psychology, 21, 21-28.

Parker, J. D., Taylor, G. J., \& Bagby, R. M. (1993a). Alexithymia and the recognition of facial expressions of emotion. Psychotherapy and Psychosomatics, 59(3-4), 197-202.

Parker, J. D. A., Taylor, G., \& Bagby, M. (1993b). Alexithymia and the processing of emotional stimuli: An experimental study. New Trends in Experimental \& Clinical Psychiatry, 9(1-2), 9-14.

Parker, J. D., Taylor, G. J., Bagby, R. M., \& Thomas, S. (1991). Problems with measuring alexithymia. Psychosomatics, 32(2), 196-202.

Parker, P. D., Prkachin, K. M., \& Prkachin, G. C. (2005). Processing of facial expressions of negative emotion in alexithymia: The influence of temporal constraint. Journal of Personality, 73(4), 1087-1107.

Plutchik, R. (1994). The psychology and biology of emotion. New York: Harper Collins College.

Pratto, F. (1994). Consciousness and automatic evaluation. In P. M. Niedenthal (Ed.), The heart's eye: Emotional influences in perception and attention (pp. 115-143). San Diego: Academic Press.

Pratto, F., \& John, O. P. (1991). Automatic vigilance: The attention-grabbing power of negative social information. Journal of Personality and Social Psychology, 61(3), 380-391.

Rohracher, H. (1960). Einführung in die Psychologie. Wien: Urban \& Schwarzenberg.

Rothermund, K., Wentura, D., \& Bak, P. (1996). Automatische Vigilanz: Aufmerksamkeitsbindung durch verhaltensrelevante soziale Information. Trierer Psychologische Berichte, 23, 1-13.

Sanchez, F. M., \& Serrano, J. M. (1997). Influencia del nivel de alexitimia en el procesamiento de estimulos emocionales en una tarea Stroop. Psicothema, 9(3), 519-527. 
Schwartz, G. M., Izard, C. E., \& Ansul, S. E. (1985). The 5-month-olds ability to discriminate facial expressions of emotion. Infant Behavior $\mathcal{E}$ Development, 8, 65-77.

Serrano, J. M., Iglesias, J., \& Loeches, A. (1992). Visual discrimination and recognition of facial expressions of anger, fear, and surprise in 4- to 6-monthold infants. Developmental Psychobiology, 25(6), 411-425.

Shiffrin, R. M., \& Schneider, W. (1977). Controlled and automatic human information-processing. 2. Perceptual learning, automatic attending, and a general theory. Psychological Review, 84(2), 127-190.

Stroop, J. R. (1935). Studies of interference in serial verbal reactions. Journal of Experimental Psychology, 18(6), 643-662.

Suslow, T. (1998). Alexithymia and automatic affective processing. European Journal of Personality, 12(6), 433-443.

Suslow, T., \& Junghanns, K. (2002). Impairments of emotion situation priming in alexithymia. Personality and Individual Differences, 32(3), 541-550.

Suslow, T., Junghanns, K., Donges, U. -S., \& Arolt, V. (2001). Alexithymia and automatic processing of verbal and facial affect stimuli. Current Psychology of Cognition, 20(5), 297-324.

Suslow, T., Ohrmann, P., \& Arolt, V. (2001). Ausgestaltung sogenannter affektiver Voraktivierungseffekte in der evaluativen Entscheidungsaufgabe: Hinweise auf automatische Vigilanz fur negative Informationen. Zeitschrift fur Psychologie, 209, 137-152.
Taylor, G. J. (2000). Recent developments in alexithymia theory and research. Canadian Journal of Psychiatry, 45(2), 134-142.

Taylor, G. J., \& Bagby, R. M. (2000). An overview of the alexithymia construct. In R. Bar-On R \& J. D. A. Parker (Eds.), The Handbook of emotional intelligence: Theory, development, assessment, and application at home, school, and in the workplace (pp. 41-67). San Francisco: Jossey-Bass.

Taylor, G. J., Bagby, R. M., \& Parker, J. D. A. (1997). Future directions. In G. J. Taylor, R. M. Bagby \& J. D. A. Parker (Eds.), Disorders of affect regulation: Alexithymia in medical and psychiatric illness (pp. 267-271). Cambridge: Cambridge University Press.

Taylor, G. J., Ryan, D., \& Bagby, R. M. (1985). Toward the development of a new Self-Report Alexithymia Scale. Psychotherapy and Psychosomatics, 44(4), 191-199.

Vermeulen, N., Luminet, O., \& Corneille, O. (2006). Alexithymia and the automatic processing of affective information: Evidence from the affective priming paradigm. Cognition $\mathcal{E}$ Emotion, 20(1), 64-91.

Williams, J. M. G. (1997). Cognitive psychology and emotional disorders. Chichester: Wiley.

Williams, J. M. G., Mathews, A., \& MacLeod, C. (1996). The emotional Stroop task and psychopathology. Psychological Bulletin, 120(1), 3-24.

Zajonc, R. B. (1980). Feeling and thinking: Preferences need no inferences. American Psychologist, 35(2), 151-175. 